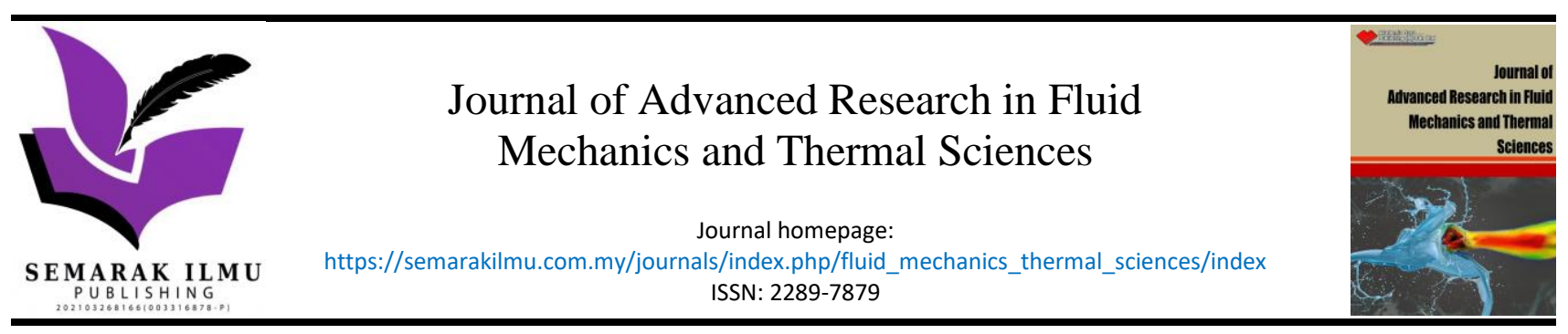

\title{
Simulations and Optimizations for a Low-Temperature Hybrid Geothermal-Solar Power Plant
}

\author{
Abdelghani Djemaa ${ }^{1}$, Abderrezak Merabet $^{2}$, Redha Rebhi ${ }^{3,4}{ }^{,}$Giulio Lorenzini ${ }^{5,}{ }^{*}$, Rachid Bessaih ${ }^{6}$, \\ Younes Menni ${ }^{7}$
}

Department of Mechanical Engineering, Laboratory of Renewable Energy and Durability Development, University of Freres Mentouri Constantine 1, Algeria

Department of Mechanical Engineering, Laboratory of Mechanical, University of Freres Mentouri Constantine 1, Algeria

3 University of Medea, Faculty of Technology, Department of Mechanical Engineering, Medea, 26000, Algeria

4 LERM - Renewable Energy and Materials Laboratory, University of Medea, Medea, 26000, Algeria

5 Department of Engineering and Architecture, University of Parma, Parco Area delle Scienze, 181/A, Parma 43124, Italy

Department of Mechanical Engineering, Laboratory LEAP, University of Freres Mentouri Constantine 1, Algeria

Department of Technology, University Centre of Naama, P.O. Box 66, Naama 45000, Algeria

\section{ARTICLE INFO}

\section{Article history:}

Received 10 September 2021

Received in revised form 5 December 2021

Accepted 9 December 2021

Available online 5 January 2022

\section{ABSTRACT}

The possibility of producing electrical power in Algeria from low geothermal and solar heat resources is addressed using a hybrid power generation hypothetical system based on a combined flash-binary cycle with equal contributions from solar and geothermal energy. To improve their efficiency, energy integration techniques were used to recover waste heat from the steam turbine by preheating the working fluid R134a in the bottoming binary, which represents $30 \%$ of the energy acquired from the ORC cycle. The Aspen HYSYS application was used for power cycle simulation and modeling. A contact between the wane pressure and the pressure at the ORC binary cycle turbine's intake must be made to obtain the greatest power out of the hybrid power plant. According to the findings, the perfect flashing pressure of the flash cycle and the optimal intake pressure of the working fluid to the binary cycle's turbine are $450 \mathrm{kPa}$ and $3340 \mathrm{kPa}$, respectively. The overall power generation and thermal efficiency of the hybrid plant were calculated to be $3823 \mathrm{~kW}$ and $16.1 \%$, respectively, at these pressures, demonstrating a significant thermodynamic advantage over each of the component systems.

\section{Introduction}

As the world's population grows, the demand for energy to power our homes, companies and communities grows as well. Renewable Energy is a type of infinite and endless energy obtained from natural resources such as the sun, wind, water, earth's heat, and plants, with the most important distinction being that it aids in climate change mitigation. Innovation and expansion of renewable energy sources are required to maintain a sustainable level of energy. Renewable energy

\footnotetext{
*Corresponding author.

E-mail address: giulio.lorenzini@unipr.it
}

https://doi.org/10.37934/arfmts.90.2.109123 
technologies convert these fuels into usable energy forms including electricity, heat, chemicals, or mechanical energy.

Solar energy, an unlimited source that is abundant and widely distributed over the planet, is frequently mentioned among the renewable energies. Electricity generated by concentrated solar systems (also known as CSP) is being marketed as a viable renewable energy source. They're essentially cylindro-parabolic mirrors that focus the sun's rays on the focal axis, which is also the location of the caloric fluid-carrying absorber tube. Mineral oil achieves a temperature of $390^{\circ} \mathrm{C}$. The heated oil is used to boil and superheat water before being sent to a steam turbine and generator system. Another less prevalent but rapidly growing source of heat and/or electricity is the basement (geothermal energy). The purpose of this study is to explore if these two resources may be combined to increase energy supply.

Geothermal energy is thermal energy that is generated and stored in the Earth in the form of high-pressure brine or hot dry rock. The term geothermal may be divided down into two parts: geo, which refers to the earth, and thermal, which refers to the heat. Because it can run 24 hours a day, seven days a week, it's also known as base load power, and conversion technologies exist that allow electricity to be created from geothermal fluids at low temperatures [1].

Many low-temperature geothermal resources $\left(100-150{ }^{\circ} \mathrm{C}\right)$ have the potential to create commercial energy, but because of their low temperatures, they are unable to do so efficiently. Sun energy may be used to boost the efficiency of geothermal power plants. There are many various types of CSP and geothermal power generation technologies, but one of the most difficult decisions to make in which technology to hybridize to improve efficiency.

In 1979, Mathur [2] published an evaluation of a hybrid solar-geothermal power plant (HSGPP) based on a binary cycle design, which looked at a number of different potential solar-geothermal hybrid topologies. He believes that solar heating from a geothermal plant creates higher-quality steam, which is a thermodynamic advantage over a stand-alone system, and that using low- to medium-grade geothermal resources makes the hybrid plant more efficient.

Lentz and Almanza [3,4] have investigated the possibility of increasing the quality of steam generated by employing a parabolic trough solar field to raise the enthalpy from geothermal well flow. The efficiency of the electric heating system enhanced at greater temperatures. Due to improved salt solubility, higher steam-water flow rates made it possible to prevent the deposition of some salts. Greenhut et al., [5] have proposed two hybrid solar geothermal systems: a fast hybrid plant and a binary supercritical hybrid plant. The findings indicated that the low-energy, low-cost heat source (geothermal) should be used to broaden the temperature range possible within its temperature constraints, while only the high-energy, high-cost heat source (solar) should be used to raise the geothermal fluid's temperature.

Astolfi et al., [6] carried out a technical-economic assessment of a hybrid geothermal solar concept that integrates an ORC geothermal power plant with a CSP system in a binary configuration. In another research, Zhou et al., [7] and Zhou [8] evaluated supercritical and subcritical binary cycles in Australian climatic circumstances to learn more about HSGPPs. According to the data, the supercritical plant produces 4-17 percent more electricity energy than the subcritical plant using the same geothermal resource. They also discover that the hybrid plant's Levelized Cost of Electricity (LCOE) is 20 percent cheaper than a stand-alone geothermal power plant under the assumptions of a supercritical binary cycle and a reservoir temperature of $150^{\circ} \mathrm{C}$.

In addition, Ghasemi et al., [9] and Ayub et al., [10] present a system in which solar heat is given to the binary cycle's working fluid (Isobutene), but the cycle temperature is limited at $182{ }^{\circ} \mathrm{C}$ to prevent chemical breakdown in the fluid. The findings showed a $17.9 \%$ increase in solar efficiency, a $5.5 \%$ enhancement in net power generation, and a $3.4 \%$ improvement in second-law efficiency, but 
only a $2 \%$ reduction in LCOE. Bonyadi et al., [11] also propose a new method for hybridizing an HSGPP, in which the primary cycle is solar energy and the lower cycle is a geothermal power plant that captures exhaust heat from the steam topping cycle. This type of hybridization system does not require the binary bottoming cycle to be physically changed or operated outside of its intended parameters due to the higher turbine input temperature, resulting in higher solar-to-electricity conversion efficiencies. Furthermore, the design reduces the use of geothermal resource, possibly prolonging the life of declining and marginal geothermal sites.

Habibollahzade et al., [12] suggested a novel design model for a hybrid geothermal solar power plant employing a solar/geothermal stack, based on analytical simulations and CFD analyses. The findings of the system's optimization revealed that raising the chimney's height to its maximum value generated more electricity. As a consequence, enhanced efficiency and low power costs are maintained throughout time, independent of climatic circumstances. In order to make use of lowtemperature geothermal resources (CPG), Garapati et al., [13] proposed a new approach employing geothermal heat as a secondary energy source for the generation of electricity by a $\mathrm{CO}_{2}$-based geothermal power producing system in various locations of Switzerland. An analytical examination of the system's performance was undertaken for different depths of the geothermal reservoir (2.5$4.5 \mathrm{~km})$ and varying turbine input temperatures $\left(100-220^{\circ} \mathrm{C}\right)$ to estimate the power and maximum efficiency.

Garapati et al., [14] investigated two hybrid geothermal systems: one utilizes $\mathrm{CO}_{2}$ as an underground heat transfer fluid with supplementary heat, while the other uses hot brine produced geologically to warm the secondary working fluid $\left(\mathrm{CO}_{2}\right)$ as part of a secondary electric cycle. They determined that the two systems tested can create $20 \%$ more electrical energy than power acquired from independent geothermal and auxiliary systems in various conditions. The ideal temperature at the turbine intake is between 100 and $200{ }^{\circ} \mathrm{C}$ when the geothermal heat input is between 50 and 70 $\%$ of the total heat input to the hybrid system. Finally, at low temperatures, direct $\mathrm{CO}_{2}$ system and the proper medium are required.

Keshvarparast et al., [15] also studied a HSGPP with an air-cooled condenser. In their research, they looked at the recuperative organic Rankine cycle for power production. McTigue et al., [16] studied five strategies for providing solar heat in a double flash GPP. With $24.3 \%$ efficiency, heating the brine after the first flash tank was the most efficient way. Bassetti et al., [17] also compared the monthly power generation of two CSP-GPP systems with and without TES. Because of the additional thermal energy stored in the TES, the CSP-GPP with TES generates 19\% more annual power than the CSP-GPP without TES.

Wan et al., [18] have proposed a concept of a HSGPP with three subsystems: a solar preheating subsystem, a flash binary power subsystem, and a binary power subsystem, with an average temperature of the geothermal source of $170{ }^{\circ} \mathrm{C}$. After a sensitivity study of the primary factors, they identified a net system power of $12.76 \mathrm{MW}$ for a solar energy input of $69.95 \%$, and the solar collecting caused the system's maximum exercise loss. Other energy systems have recently been examined for diverse designs, different fluids, and varied operating circumstances] in recent studies [19-41].

The majority of the previous research used thermo-solar hybrid power plants with a medium enthalpy of roughly $150^{\circ} \mathrm{C}$; however, in our investigation, a geothermal source is used with a low enthalpy of $98^{\circ} \mathrm{C}$. The overall aim of this optimization is to assess and enhance the efficiency of a flash-binary combined cycle solar-geothermal hybrid power plant that generates electricity, with a focus a recovering waste heat from the steam turbine and the possibility of preheating the R134a working fluid in the bottoming binary cycle. 


\section{Data, Methodology and Studied Layout}

Solar and geothermal energy are among the renewable energies used in our study. The suggested flash-binary system is depicted in Figure 1 . The system is made up of three components: a flash cycle as the primary solar-geothermal system, a simple-pressure evaporation ORC as the binary unit, and a parabolic trough collector for concentrating sunlight.

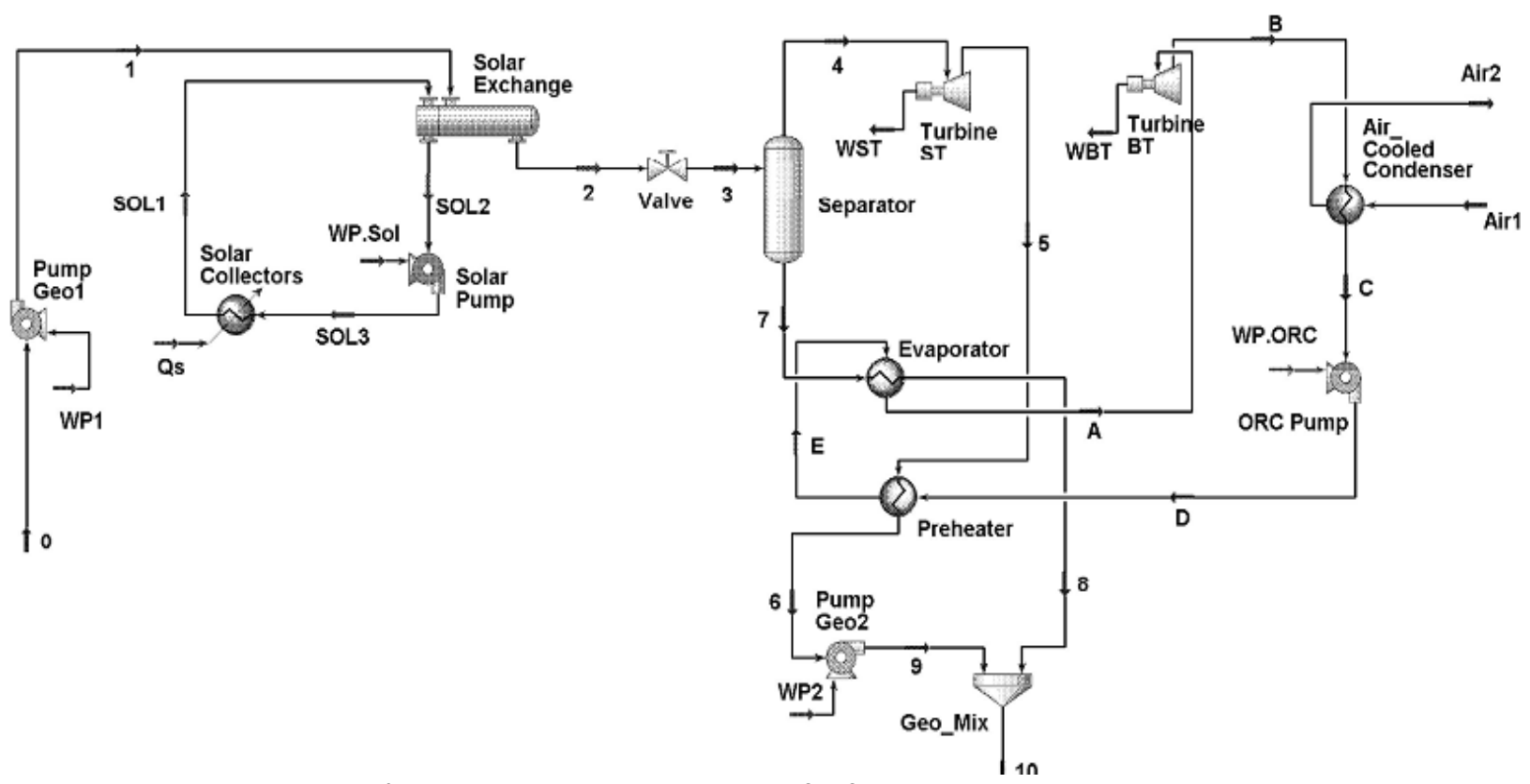

Fig. 1. Aspen Hysys' schematic representation of a flash-binary plant using solar brine heat

At a temperature of $98^{\circ} \mathrm{C}$ and a pressure of 5 bar, brine geothermal enters the power plant at a total mass flow rate of $100 \mathrm{~kg} / \mathrm{s}$. To facilitate flashing and steam separation in this study, the lowtemperature brine is pumped to a higher pressure before being heated with solar energy to a medium temperature; the geothermal fluid is considered to be saturated at $153.2^{\circ} \mathrm{C}$ and 5.2 bar.

The topping turbine (ST) is a back-pressure steam turbine that supplies additional power to the binary cycle (BT). Before being injected again, steam from the turbine (ST) condenses in the preheater preheating the binary cycle's working fluid. The hot-separated brine, which still has a high enthalpy, is utilized in the binary working fluid's last heating phase before being reunited with the steam condensate and reinjected.

The flash-binary plant with solar brine heating generating system may achieve high energy conversion efficiency since the advantage of using a binary organic cycle is an increase in the system's total efficiency. R134a is also the ideal fluid for low temperature applications such ORC binary cycle power plants, according to Al-Sulaiman [42], Tchanche et al., [43] and DiPippo [44]. The operating conditions of the power plant are summarized in Table 1. 


\section{Table 1}

Simulation conditions for the hybrid plant

\begin{tabular}{|c|c|c|c|}
\hline Parameters & Value & Parameters & Value \\
\hline Mass flow of brine & $100 \mathrm{~kg} / \mathrm{s}$ & Heat transfer fluid (HTF) & Therminol,VP-1 \\
\hline Organic working fluid & $\mathrm{R} 134 \mathrm{a}$ & (HTF) maximum temperature & $393{ }^{\circ} \mathrm{C}$ \\
\hline Approach point temperature diff. in evaporator & $5^{\circ} \mathrm{C}$ & Direct Normal Irradiation (DNI) & $800 \mathrm{~W} / \mathrm{m}^{2}$ \\
\hline Pinch point temperature difference & & Sol-Thermal Efficiency & $80 \%[45]$ \\
\hline Evaporator & $5^{\circ} \mathrm{C}$ & Optical Efficiency & $56.8 \%[45]$ \\
\hline Preheater & - & & \\
\hline Condenser & $3^{\circ} \mathrm{C}$ & & \\
\hline Isentropic efficiency of steam turbine & $85 \%$ & & \\
\hline Isentropic efficiency of binary turbine & $85 \%$ & Ambient temperature & $18^{\circ} \mathrm{C}$ \\
\hline Pump efficiency & $70 \%$ & Ambient pressure & $101.3 \mathrm{kPa}$ \\
\hline
\end{tabular}

\section{Mathematical Modelling}

The principles of conservation of mass and energy will be applied to relevant open systems or control volumes in this investigation. The equations will be used to balance the flash chamber, turbines, pumps, and heat exchangers, as well as other stable and unsteady systems. The Aspen HYSYS process simulation program, which models the system thermodynamics, is used to calculate the thermodynamic performance. Thermodynamic modeling necessitates the computation of inherent thermodynamic properties such as entropy and enthalpy. The following fundamental equations reflect the mass and energy balances for each component of the cycle:

$\sum \dot{m}_{\text {in }}=\sum \dot{m}_{\text {out }}$

$\dot{Q}+\dot{W}=\sum m_{\text {out }} \cdot h_{\text {out }}-\sum m_{\text {ln }} \cdot h_{\text {in }}$

The mass flow rate is $\dot{m}$, the net heat is $\dot{Q}$, the work input is $\dot{W}$, and the enthalpy is $h$. The general balancing equation is as follows:

$$
\text { Accumulation }=\text { Input }+ \text { Generation }- \text { Output }- \text { Consumption }
$$

Generation is generally made up of the words (Generation - Consumption), with a positive value for net generation and a negative value for net consumption.

$\dot{W}_{\text {net }}=\dot{W}_{\text {turb }}-\dot{W}_{\text {pumps }}-\dot{W}_{A C C}$

$\dot{W}_{n e t}=\dot{W}_{S T}+\dot{W}_{B T}-\dot{W}_{P 1}-\dot{W}_{P 2}-\dot{W}_{P, O R C}-0.25 \dot{m}_{A i r}$

Where, $W_{A C C}$ refers to the power consumption of ACC fans (Air-Cooled Condenser). The air-cooled condenser's fan produces a relatively constant $0.25 \mathrm{~kW}$ per kg/s of air flow through the ACC [5]. During cycle optimization, this result is used as a fixed parameter. Table 2 shows the mass and energy balance equations for each component of the cycle. 
Table 2

The mass and energy formulae for the components of the hybrid cycle

\begin{tabular}{lll}
\hline Component & Mass balance equation & Energy balance equation \\
\hline Solar pump & Solar cycle & \\
Solar Collectors & $\dot{m}_{\text {sol3 }}=\dot{m}_{\text {sol2 }}$ & $\dot{W}_{P \text { sol }}=\dot{m}_{0}\left(h_{\text {sol3 }}-h_{\text {sol2 }}\right)$ \\
Solar Exchanger & $\dot{m}_{\text {sol3 }}=\dot{m}_{\text {sol } 1}$ & $\dot{Q}_{u}=\dot{m}_{\text {oil }} C_{P, \text { oil }}\left(T_{\text {sol } 1}-T_{\text {sol3 }}\right)$ \\
& $\dot{m}_{1}=\dot{m}_{2} \& \dot{m}_{\text {sol } 1}=\dot{m}_{\text {sol2 }}$ & $\dot{m}_{0}\left(h_{2}-h_{1}\right)=\dot{m}_{\text {sol }}\left(h_{\text {sol } 1}-h_{\text {sol2 }}\right)$ \\
Pump geo1 & Flash cycle & \\
Valve & $\dot{m}_{0}=\dot{m}_{1}$ & $\dot{W}_{P 1}=\dot{m}_{0}\left(h_{1}-h_{0}\right)$ \\
Separator & $\dot{m}_{2}=\dot{m}_{3}$ & $\dot{m}_{2} h_{3}=\dot{m}_{3} h_{3}$ \\
Turbine ST & $\dot{m}_{3}=\dot{m}_{4}+\dot{m}_{7}$ & $\dot{m}_{3} h_{3}=\dot{m}_{4} h_{4}+\dot{m}_{7} h_{7}$ \\
Pump geo 2 & $\dot{m}_{4}=\dot{m}_{5}$ & $\dot{W}_{S T}=\dot{m}_{4}\left(h_{4}-h_{5}\right)$ \\
Geo Mix & $\dot{m}_{6}=\dot{m}_{9}$ & $\dot{W}_{P 2}=\dot{m}_{6}\left(h_{9}-h_{6}\right)$ \\
& $\dot{m}_{10}=\dot{m}_{8}+\dot{m}_{9}$ & $\dot{m}_{10} h_{10}=\dot{m}_{8} h_{8}+\dot{m}_{9} h_{9}$ \\
ORC Pump & ORC cycle & \\
Preheater & $\dot{m}_{C}=\dot{m}_{D}$ & $\dot{W}_{P, O R C}=\dot{m}_{O R C}\left(h_{D}-h_{C}\right)$ \\
Evaporator & $\dot{m}_{5}=\dot{m}_{6} \& \dot{m}_{E}=\dot{m}_{D}$ & $\dot{m}_{5}\left(h_{6}-h_{5}\right)=\dot{m}_{O R C}\left(h_{D}-h_{E}\right)$ \\
Turbine BT & $\dot{m}_{7}=\dot{m}_{8} \& \dot{m}_{E}=\dot{m}_{A}$ & $\dot{m}_{7}\left(h_{8}-h_{7}\right)=\dot{m}_{O R C}\left(h_{E}-h_{A}\right)$ \\
Air Cooled Condenser & $\dot{m}_{A}=\dot{m}_{B}$ & $\dot{W}_{B T}=\dot{m}_{O R C}\left(h_{A}-h_{B}\right)$ \\
\hline
\end{tabular}

The thermal efficiency of the working fluid may be calculated as follows:

$\eta_{t h}=\frac{\text { Net work output }}{\text { Heat input }}=\frac{\dot{W}_{\text {net }}}{\dot{Q}_{\text {in }}}=\frac{\dot{W}_{\text {net }}}{\dot{Q}_{g e o}+\dot{Q}_{\text {sol }}}$

Because solar and geothermal energy are of equal value, if the heat input ratio is equal to or less to 1 , the ratio is defined as follows [46]:

$\dot{Q}_{\text {ratio }}=\frac{\dot{Q}_{\text {sol }}}{\dot{Q}_{\text {geo }}}$

The solar heat gives to the flash -ORC combined cycle, i.e., the net solar heat input, was obtained by remove the heat losses in the solar field from the raw solar heat input. This section's equations are mainly based on Baghernejad and Yaghoubi [45]:

The solar radiation incidence on the parabolic trough collector is:

$\dot{Q}_{i}=$ DNI. $N_{\text {PTSC }} \cdot A_{\text {collector }}=$ DNI. $N_{\text {PTSC }} \cdot W_{O} \cdot L$

The aperture area is calculated as follows:

$A_{\text {collector }}=W_{O} \cdot L$

where $L$ and $W_{0}$ are the length and width of the collector (module), respectively. Due to losses, the energy obtained while opening a parabolic reflector is diminished before reaching the absorber tube. The usable energy provided to the absorber per unit aperture area is given by:

$\dot{Q}_{a}=\dot{Q}_{i} \cdot \eta_{\text {optical }}$ 
with $\eta_{\text {optical }}$ is the efficiency for parabolic trough collectors, defined as:

$\eta_{\text {optical }}=\rho \cdot \gamma \cdot \tau \cdot \alpha \cdot K$

where $\rho, \gamma, \tau, \alpha$, and $K$ denote the mirror's reflectance, intercept factor, glass cover transmittance, receiver absorbance, and incidence angle modifier, respectively.

For a single collector, the usable heat delivered to the heat transfer fluid through the receiver tube is calculated as follows:

$\dot{Q}_{\text {sol }}=D N I \cdot W_{O} \cdot L \cdot \eta_{\text {ptical }} \cdot \eta_{\text {sol-thermal }}$

\section{Findings and Analysis}

To create and manufacture power using geothermal energy from existing resources in the region (Hammam DBAGH) in northeastern Algeria, a basin near W. Guelma whit considerable mass flow 100 $\mathrm{kg} / \mathrm{s}$ and a temperature of $98^{\circ} \mathrm{C}$ [47]. Algeria is one of the sunniest places on the planet, which simulates the combination of the two energies to generate electricity. In addition to solar energy, Algeria is one of the nations in the world and Mediterranean basin with the most solar resources, with $169,000 \mathrm{TWh} /$ year for thermal solar. The daily energy received on a horizontal surface of $1 \mathrm{~m}^{2}$ over most of the national territory is in the order of $5 \mathrm{kWh}$, or roughly $1700 \mathrm{kWh} / \mathrm{m}^{2} /$ year in the north and $2263 \mathrm{kWh} / \mathrm{m}^{2} /$ year in the south [48]. This peculiarity promotes the coupling of the two energies in order to generate electricity.

In this simulation, the collectors are LS-3 parabolic trough collectors with Therminol VP-1 oil as the HTF. Furthermore, the cold brine is injected at a temperature of $70^{\circ} \mathrm{C}$ to eliminate salting scaling problems during operation. To examine the trends of the studied features across the year, a typical summer day, June 21, was chosen. This portion of the research presents the simulation findings for the proposed hybrid power plant, which employs the single-pressure ORC cycle to recover waste heat from the steam turbine. The suggested hybrid power plant has three units: a geothermal flash cycle as the core unit, a single-press ORC cycle as a binary unit, and a parabolic trough collector to concentrate sunlight, as previously indicated. To begin, it is necessary to evaluate the model's validity to previous research in order to verify the obtained results. The results of the Aspen HYSYS optimization process are then exhibited in a steady state. Finally, several element's effects on cycle performance are presented.

\subsection{Comparison of the Performance}

A thermodynamic model of the combined single flash and ORC plant geothermal-solar power plant is developed in the application Aspen HYSYS using the equations from Section 3. The particular work output computed by the model is compared to the specific work output reported in the literature for the KBFB geothermal power generation plant investigated by Wang et al., [49] to validate that the model's findings are correct. Table 3 summarizes the results of this comparison. 
Table 3

The mass and energy formulae for the components of the hybrid cycle

\begin{tabular}{llll}
\hline Performance parameters & Unit & Present results & Kalina-based flash-binary [49] \\
\hline Flash pressure & Bar & 5 & 5 \\
Flash Temperature & ${ }^{\circ} \mathrm{C}$ & 170 & 170 \\
Mass flow rate (geothermal) & $\mathrm{kg} / \mathrm{s}$ & 10 & 10 \\
$\Delta$ T pinch & ${ }^{\circ} \mathrm{C}$ & 11.4 & 11.5 \\
Binary turbine inlet pressure & $\mathrm{Bar}$ & 34.00 & 30.00 \\
Binary turbine inlet temperature & ${ }^{\circ} \mathrm{C}$ & 140.40 & 131.89 \\
Steam turbine power & $\mathrm{kW}$ & 144 & 150.38 \\
Binary turbine power & $\mathrm{kW}$ & 451.5 & 273.89 \\
Pump's power & $\mathrm{kW}$ & 42.5 & 10.58 \\
Plant Net power & $\mathrm{kW}$ & 553 & 413.68 \\
\hline
\end{tabular}

For all systems, the present ORC cycle has two heat exchangers interacting with the working fluid and only one condenser, However, the Kalina cycle in a study by Wang et al., [49] has just one regenerator and two condensers. This causes the mass flow rate of the working fluid to vary significantly depending on the amount of heat available from the sun, meaning that the state points in these two cycles are not equivalent. The present findings, as can be seen, have a higher net power than the KBFB geothermal power generating system described in a study by Wang et al., [49]. For the suggested binary cycle, an air-cooled condenser has been as a comparison.

The results reported in Table 2 shows that the net power of the present model is greater than that presented by Wang et al., [49], as shown in Figure 2 where the diagrams represent the variation of the quantity of energy according to the temperature or the level of the exchangers with a binary cycle for the two cycles. The addition of a recovery exchanger (preheater or condenser) (Figure 2(a)) saves a significant amount of energy for the ORC cycle due to the steam used, which arrives from the back-pressure turbine after expansion to preheat the binary fluid R134a before evaporating and overheat in the second exchanger (evaporator) (Figure 2(b)). On the other hand, the cycle analyzed by Wang et al., [49] utilizes a single energy recovery exchanger (Figure 2(c)), indicating that the power difference between the two models is virtually equal to the power provided by the binary cycle's ORC turbine.

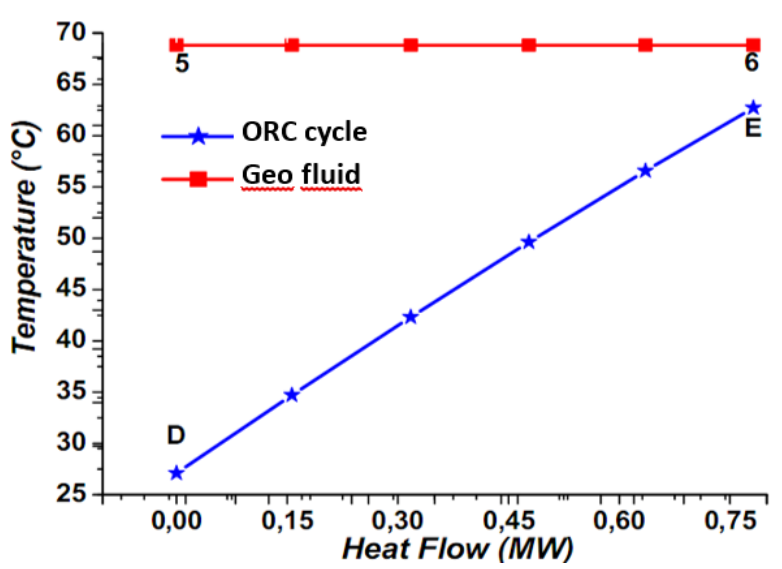

(a)

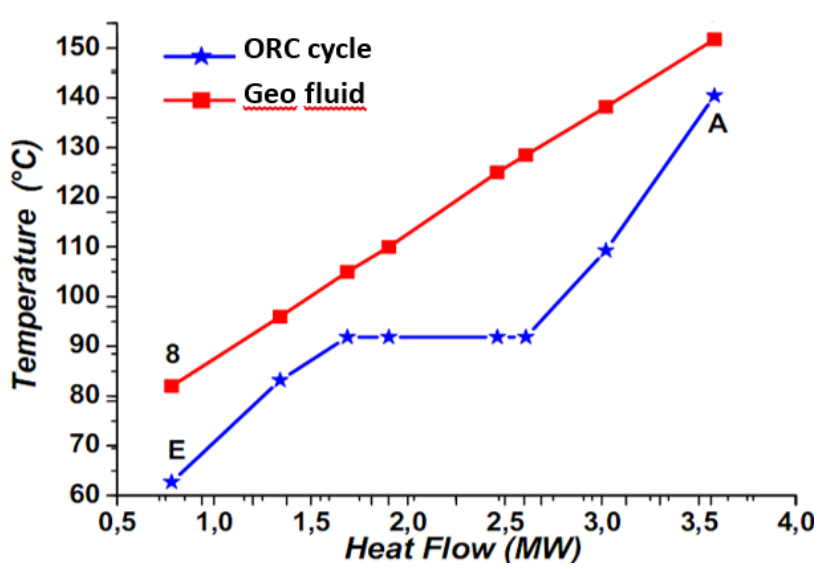

(b) 


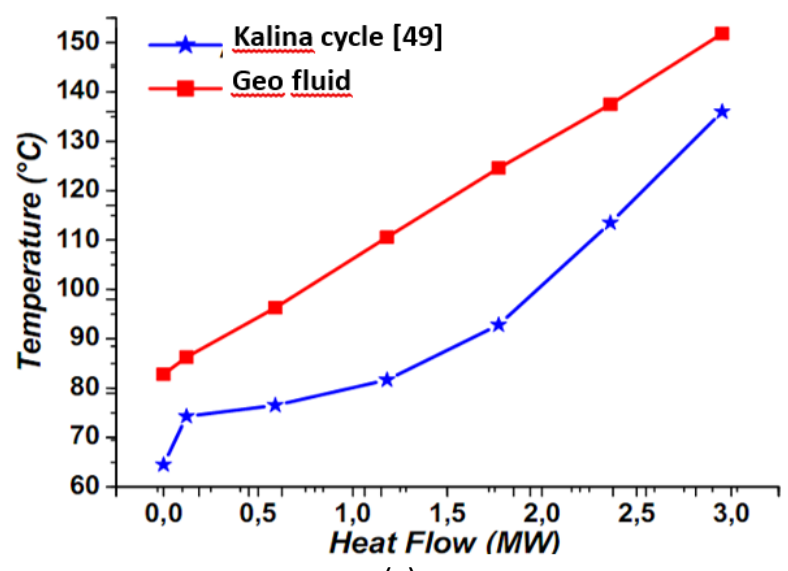

(c)

Fig. 2. Temperature-heat transfer diagram for (a) preheater (b) evaporator and (c) recuperator

\subsection{Numerical Analysis}

This section presents the results of the simulation for a combined flash-binary plant with solar brine heating. Aspen HYSYS, a process simulation package, was used to simulate and optimize the solar-geothermal system. As a result, air cooling is the most viable way for cooling a binary ORC plant [7]. Table 4 shows the exact conditions for the system's simulation and analysis, while Table 5 reports the system's performance.

\section{Table 4}

Simulation results of each stream of the power plant [for $P_{3}=3$ bar and $P_{D}=19.25$ bar]

\begin{tabular}{|c|c|c|c|c|c|c|c|}
\hline State & Fluid & $\dot{m}[\mathrm{~kg} / \mathrm{s}]$ & $\mathrm{T}\left[{ }^{\circ} \mathrm{C}\right]$ & $\mathrm{P}$ [bar] & Quality & $\mathrm{h}[\mathrm{kJ} / \mathrm{kg}]$ & $\mathrm{s}[\mathrm{kJ} / \mathrm{kg} . \mathrm{C}]$ \\
\hline 0 & $\mathrm{H}_{2} \mathrm{O}$ & 100 & 98 & 5 & liquid & 414 & 3.965 \\
\hline 1 & $\mathrm{H}_{2} \mathrm{O}$ & 100 & 98 & 5.2 & liquid & 414 & 3.965 \\
\hline 2 & $\mathrm{H}_{2} \mathrm{O}$ & 100 & 153.2 & 5.2 & liquid & 646 & 4.546 \\
\hline 3 & $\mathrm{H}_{2} \mathrm{O}$ & 100 & 133.42 & 3 & 0.03873 & 646 & 3.5516 \\
\hline 4 & $\mathrm{H}_{2} \mathrm{O}$ & 3.873 & 133.42 & 3 & 1 & 2725.3 & 9.7081 \\
\hline 5 & $\mathrm{H}_{2} \mathrm{O}$ & 3.873 & 68.82 & 0.3 & 0.914 & 2411.3 & 9.8701 \\
\hline 6 & $\mathrm{H}_{2} \mathrm{O}$ & 3.873 & 68.50 & 0.3 & liquid & 288.1 & 3.6278 \\
\hline 7 & $\mathrm{H}_{2} \mathrm{O}$ & 96.13 & 133.42 & 3 & liquid & 561.43 & 4.3440 \\
\hline 8 & $\mathrm{H}_{2} \mathrm{O}$ & 96.13 & 68.53 & 3 & liquid & 263.7 & 4.3440 \\
\hline 9 & $\mathrm{H}_{2} \mathrm{O}$ & 96.13 & 70.10 & 3 & liquid & 300 & 3.6465 \\
\hline 10 & $\mathrm{H}_{2} \mathrm{O}$ & 100 & 70.04 & 3 & liquid & 300 & 3.6457 \\
\hline$A$ & R134a & 126 & 125 & 19.3 & 1 & 309.5 & 1.9562 \\
\hline B & R134a & 126 & 51.7 & 7.0 & 1 & 286.35 & 1.9676 \\
\hline C & R134a & 126 & 25.6 & 7.0 & liquid & 232 & 1.1774 \\
\hline D & R134a & 126 & 27.11 & 19.3 & liquid & 238 & 1.1782 \\
\hline$E$ & R134a & 126 & 61.52 & 19.3 & liquid & 297.44 & 1.3830 \\
\hline S1 & Therminol, VP-1 & 99.85 & 393 & 13 & - & 780.5 & 0.9507 \\
\hline S2 & Therminol, VP-1 & 99.85 & 293 & 10 & - & 548.5 & 0.5751 \\
\hline S3 & Therminol, VP-1 & 99.85 & 293.1 & 15 & - & 549.5 & 0.5755 \\
\hline Air1 & Air & 4401 & 18 & 1 & - & 291 & 4.0623 \\
\hline Air2 & Air & 4401 & 25 & 1 & - & 298 & 4.0858 \\
\hline
\end{tabular}


Table 5

Performance of the hybrid plant [for $\mathrm{P}_{3}=3$ bar and $\mathrm{P}_{\mathrm{D}}=19.25 \mathrm{bar}$ ]

\begin{tabular}{lll}
\hline Term & Value & Unit \\
\hline Steam turbine power & 1216 & \\
Pump power 1 & 2.80 & \\
Pump power 2 & 1.43 & $\mathrm{~kW}$ \\
Binary turbine power & 2960 & \\
ORC pump power & 159.7 & \\
Fan power & 1100.3 & \\
Plant Net power & 2912 & \\
Heat delivered to the cycle & 23000 & $\%$ \\
Energy efficiency & 12.7 & \\
\hline
\end{tabular}

\subsection{Thermodynamic Analysis}

The plant net power is influenced by flash pressure, which is one of the primary parameters for optimizing the binary wane hybrid system. The solar heat transfer fluid heated the brine to $153.2{ }^{\circ} \mathrm{C}$, and then the brine was flashed to pressures ranging from 3 and 5.2 bar. The findings of this analysis are shown in Table 6 . The net power and temperature of the $\mathrm{R} 134 \mathrm{a}$ rose as the flash pressure increased.

\section{Table 6}

Flash-binary hybrid results from varying flash pressure

\begin{tabular}{llllllll}
\hline $\begin{array}{l}\text { Flash } \\
\text { pressure }\end{array}$ & $\begin{array}{l}\text { WF } \\
\text { pressure }\end{array}$ & $\begin{array}{l}\text { WF Max } \\
\text { Temp. }\end{array}$ & $\begin{array}{l}\text { Steam turbine } \\
\text { power }\end{array}$ & $\begin{array}{l}\text { Binary turbine } \\
\text { power }\end{array}$ & $\begin{array}{l}\text { Parasitic } \\
\text { power }\end{array}$ & $\begin{array}{l}\text { Net } \\
\text { power }\end{array}$ & $\begin{array}{l}\text { Thermal } \\
\text { eff. }\end{array}$ \\
\hline (bar) & (bar) & $\left({ }^{\circ} \mathrm{C}\right)$ & $(\mathrm{kW})$ & $(\mathrm{kW})$ & $(\mathrm{kW})$ & $(\mathrm{kW})$ & $\%$ \\
3 & 19.3 & 125.0 & 1216 & 2960 & 1264.3 & 2912 & 12.7 \\
3.3 & 23.6 & 136.7 & 1063 & 3505 & 1308.6 & 3260 & 14.2 \\
3.5 & 27.0 & 133.8 & 957 & 3845 & 1344.6 & 3457 & 15.0 \\
4 & 30.4 & 138.5 & 682 & 4163 & 1387.3 & 3458 & 15.0 \\
4.5 & 33.4 & 142.8 & 400 & 4850 & 1426.8 & 3823 & 16.1 \\
5.2 & 37.1 & 148.2 & - & 4712 & 1450.0 & 3262 & 14.2 \\
\hline
\end{tabular}

The back pressure of the steam turbine was 0.3 bar, as low as feasible, while the outlet pressure of the binary turbine was between 7 and 8 bars for the specified ideal values of the combined power plant, as shown in Table 6 . According to the findings, the yields, as well as the gross power of the binary turbine, increase as the flash pressure increases to reach a maximum value of 4.5 bar. However, the steam turbine changes in the opposite direction. This is because higher flash pressures produce less vapor and lower flash pressures produce vapor at lower temperatures.

\subsubsection{Effect of flash pressure on the steam turbine power}

Changes in flash pressure have an impact on steam turbine production ( $P$ flash), as shown in Figure 3. When the separator pressure is increased from 3 to 5.2 bar, the steam turbine's power output is lowered. Raising the separation pressure has two opposing effects on the steam turbine produced power, it decreases the flow rate of steam, decreasing the produced power, and it raises the turbine input enthalpy, resulting in higher steam turbine power generation. The combined effect of these two opposing forces resulted in a decrease in the steam turbine's power output. This is because lowering the mass flow has a higher influence than increasing the enthalpy drop over the steam turbine. 


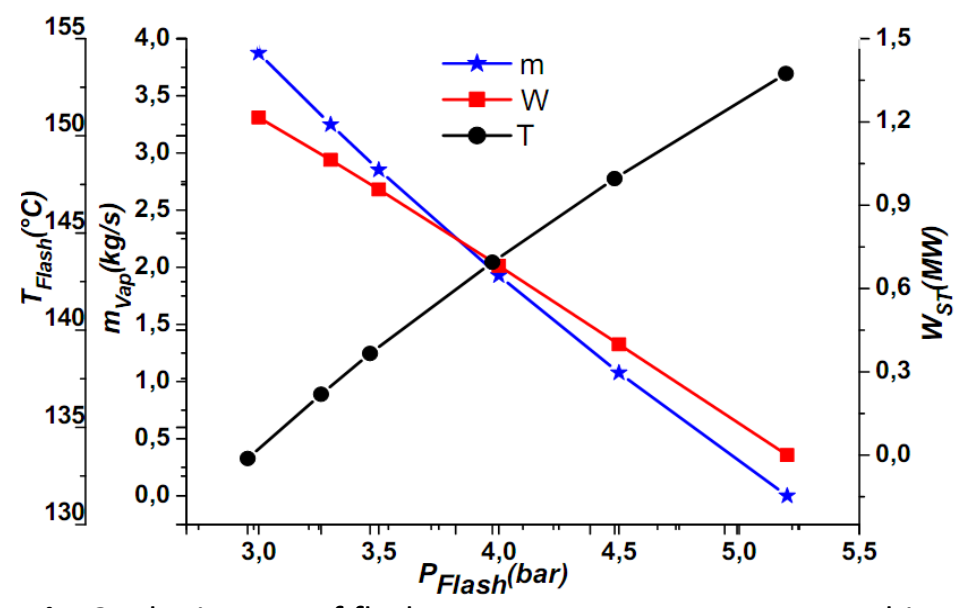

Fig. 3. The impact of flash $P$ on power output steam turbine

\subsubsection{Effect of flash pressure on the binary turbine power}

The back pressure steam turbine receives the dry vapors from the separator, which are then condensed in the condenser, which is the binary cycle's preheater. As a result, the heat of vapor condensation warms the binary cycle's working fluid. Furthermore, in the binary cycle, the hot separated brine, which still has a high enthalpy, is utilized to evaporate the working fluid, resulting in higher power output. Because the exhaust steam and separated brine provide more energy to the ORC cycle, the binary turbine's power output rises to a maximum of $4850 \mathrm{~kW}$ before falling back to $4712 \mathrm{~kW}$ for flash pressures 4.5 and 5.2 bars respectively, the latter corresponds to the saturation pressure, so the flow of dry steam is cancelled, infecting the supply of the ORC cycle, and therefore the plant (Figure 4).

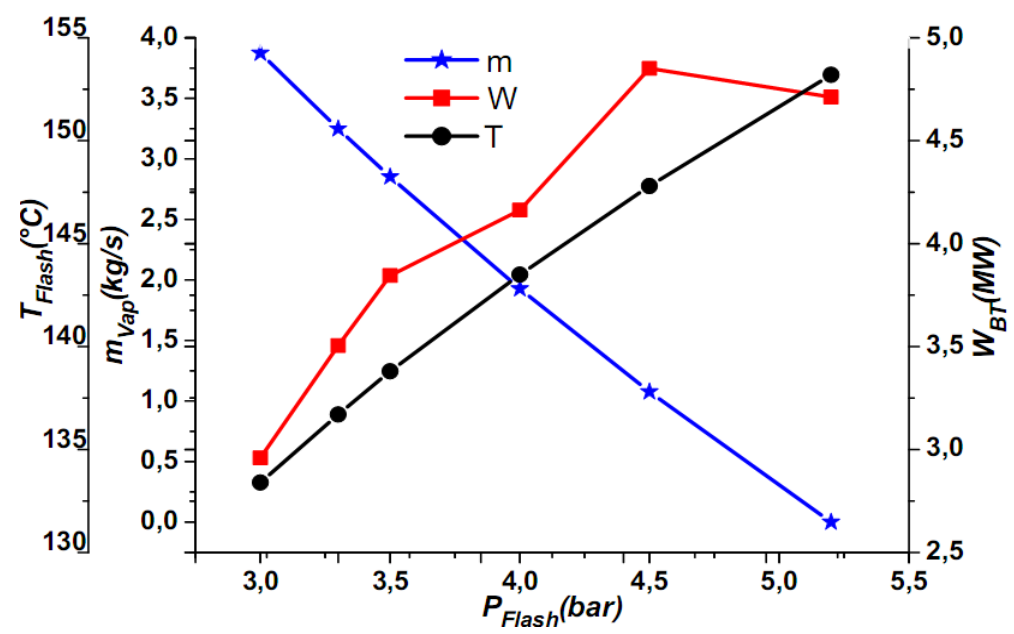

Fig. 4. The impact of flash P on the ORC turbine's power output

\subsubsection{Effect of flash pressure on the net power output of a hybrid system}

The system's whole performance is determined by flash pressure. According to the research, when the flash pressure rises, the system net power rises at first, peaks a peak ( $\mathrm{P}$ flash $=4.5$ bar), and then drops, as illustrated in Figure 5, due to an increase in binary turbine power and a decrease in steam turbine power. As a result, this figure is often considered to be the ideal flashing pressure for power plant operation. It can also be shown that the energy efficiency of the combined installation 
varies in lockstep with the system's net output power. At this optimum pressure value, the hybrid power plant's total net production and energy efficiency were calculated to be $3823 \mathrm{~kW}$ and 16.1 percent, respectively.

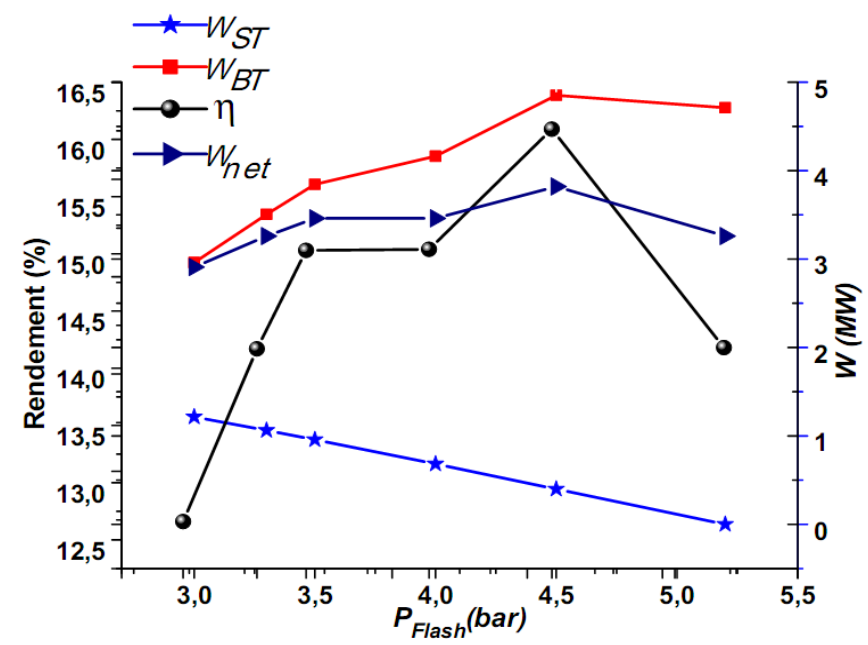

Fig. 5. The impact of flash pressure on the system's power output

\section{Concluding Remarks}

This research involved simulations and improvements for a hypothetical hybrid geothermal-solar power plant with single flash/binary that might be built in Algeria's northeast. As a result, all of the study variables were selected based on the geothermal and insolation conditions found in Algeria's northeast, namely in the Hammam DBAGH region (W. Guelma). The flashing pressure and ORC pressure were set for the hybrid unit's maximum output power. In summary, the following are the main findings of the present analysis

i. The development of a revolutionary hybrid geothermal-solar flash-binary system, in which solar energy is successfully utilized to improve the quality of geothermal energy, resulting in an increase in system power generating capacity.

ii. In order to exploit the energy used to condensate the vapors from the steam turbine; we used this energy for the preheating of the ORC cycle fluid.

iii. Due to the additional energy contributed by the preheating exchanger in the ORC cycle, which is approximately equivalent to $1 / 3(8 \mathrm{MW}$ ) of the energy required by the evaporator ( $28 \mathrm{MW})$, the cycle evaluated in this analysis generates a greater net power by $25 \%$ than the one studied by Wang et al., [49].

iv. The Kalina cycle is not superior than the ORC from a thermodynamic stand point when using medium-temperature sources with a comparatively lower temperature of geothermal water [50].

v. According to the hybrid system's sensitivity analysis, the evaporation pressure and flash pressure are the most sensitive to net power production.

vi. Using a hybrid system power plant, geothermal and solar energy may be successfully exploited for power generation. In this analysis, it has been established through thermodynamic modeling and simulation using the process of simulation package 'Aspen HYSYS', by varying the pressure value of the separator, change down from the saturation pressure, $\mathrm{P}=5.2$ bar till to $\mathrm{P}=3$ bar with an increment of 0.5 bars, allows us to find the 
optimum separator pressure $\mathrm{P}=4.5$ bar, and a pressure at the binary cycle turbine inlet equal to 33.4 bar.

vii. Theoretical calculations reveal that operating the plant at 4.5 bar flash pressure and 33.4 bars pressure during the ORC cycle may produce up to $3823 \mathrm{~kW}$ of power with a $16.1 \%$ efficiency.

viii. The concept of a hybrid geothermal solar power plant is to utilize the heat of geothermal sources relatively at low temperature and the relatively high temperature heat from solar to provide a significant thermodynamic advantage comparing to the separate systems.

All investigations have been optimized for a possible installation for this kind of power plant in the (Hammam DEBAGH) at low temperature in northeastern Algeria geothermal field.

Finally, from a strictly thermodynamic standpoint, this methodology gives a meaningful appraisal of hybridization. Economic incentives are not taken into consideration in this section's conclusion. Additionally, the energetic analysis and the impacts of various parameters such as the temperature of the solar field's thermal source surface may be evaluated. For certain settings, a new sort of binary cycle, Kalina, instead of an ORC, can be utilized, perhaps leading to better thermodynamic performance. For the geothermal source, the use of other possible working fluids, particularly $\mathrm{CO}_{2}$. However, Aspen simulations have yet to investigate and assess these first ideas for thermodynamic supremacy.

\section{References}

[1] Shi, Xiaojun, and Defu Che. "A combined power cycle utilizing low-temperature waste heat and LNG cold energy." Energy Conversion and Management 50, no. 3 (2009): 567-575. https://doi.org/10.1016/i.enconman.2008.10.015

[2] Mathur, Prem Narain. An assessment of solar-geothermal hybrid system concepts. Vol. 1101. Department of Energy, 1979. https://doi.org/10.2172/5605900

[3] Lentz, Álvaro, and Rafael Almanza. "Solar-geothermal hybrid system." Applied Thermal Engineering 26, no. 14-15 (2006): 1537-1544. https://doi.org/10.1016/i.applthermaleng.2005.12.008

[4] Lentz, Álvaro, and Rafael Almanza. "Parabolic troughs to increase the geothermal wells flow enthalpy." Solar Energy 80, no. 10 (2006): 1290-1295. https://doi.org/10.1016/i.solener.2006.04.010

[5] Greenhut, Andrew D., Jefferson W. Tester, Ronald DiPippo, Randall Field, Christopher Love, Kenneth Nichols, Chad Augustine et al. "Solar-geothermal hybrid cycle analysis for low enthalpy solar and geothermal resources." Proceedings World Geothermal Congress (2010).

[6] Astolfi, Marco, Luca Xodo, Matteo C. Romano, and Ennio Macchi. "Technical and economical analysis of a solargeothermal hybrid plant based on an Organic Rankine Cycle." Geothermics 40, no. 1 (2011): 58-68. https://doi.org/10.1016/j.geothermics.2010.09.009

[7] Zhou, Cheng, Elham Doroodchi, and Behdad Moghtaderi. "An in-depth assessment of hybrid solar-geothermal power generation." Energy Conversion and Management $74 \quad$ (2013): 88-101. https://doi.org/10.1016/j.enconman.2013.05.014

[8] Zhou, Cheng. "Hybridisation of solar and geothermal energy in both subcritical and supercritical Organic Rankine Cycles." Energy Conversion and Management 81 (2014): 72-82. https://doi.org/10.1016/i.enconman.2014.02.007

[9] Ghasemi, Hadi, Elysia Sheu, Alessio Tizzanini, Marco Paci, and Alexander Mitsos. "Hybrid solar-geothermal power generation: Optimal retrofitting." Applied Energy $131 \quad$ (2014): $158-170$. https://doi.org/10.1016/i.apenergy.2014.06.010

[10] Ayub, Mohammad, Alexander Mitsos, and Hadi Ghasemi. "Thermo-economic analysis of a hybrid solar-binary geothermal power plant." Energy 87 (2015): 326-335. https://doi.org/10.1016/j.energy.2015.04.106

[11] Bonyadi, Nima, Evan Johnson, and Derek Baker. "Technoeconomic and exergy analysis of a solar geothermal hybrid electric power plant using a novel combined cycle." Energy Conversion and Management 156 (2018): 542-554. https://doi.org/10.1016/j.enconman.2017.11.052

[12] Habibollahzade, Ali, Ehsan Houshfar, Mehdi Ashjaee, and Khalil Ekradi. "Continuous power generation through a novel solar/geothermal chimney system: Technical/cost analyses and multi-objective particle swarm optimization." Journal of Cleaner Production 283 (2021): 124666. https://doi.org/10.1016/j.jclepro.2020.124666

[13] Garapati, Nagasree, Benjamin M. Adams, Mark R. Fleming, Thomas H. Kuehn, and Martin O. Saar. "Combining brine or $\mathrm{CO}_{2}$ geothermal preheating with low-temperature waste heat: A higher-efficiency hybrid geothermal power system." Journal of $\mathrm{CO}_{2}$ Utilization 42 (2020): 101323. https://doi.org/10.1016/j.jcou.2020.101323 
[14] Garapati, Nagasree, Benjamin M. Adams, Jeffrey M. Bielicki, Philipp Schaedle, Jimmy B. Randolph, Thomas H. Kuehn, and Martin O. Saar. "A hybrid geothermal energy conversion technology-a potential solution for production of electricity from shallow geothermal resources." Energy Procedia 114 (2017): 7107-7117. https://doi.org/10.1016/i.egypro.2017.03.1852

[15] Keshvarparast, Adele, Seyed Soheil Mousavi Ajarostaghi, and Mojtaba Aghajani Delavar. "Thermodynamic analysis the performance of hybrid solar-geothermal power plant equipped with air-cooled condenser." Applied Thermal Engineering 172 (2020): 115160. https://doi.org/10.1016/j.applthermaleng.2020.115160

[16] McTigue, Joshua D., Jose Castro, Greg Mungas, Nick Kramer, John King, Craig Turchi, and Guangdong Zhu. "Hybridizing a geothermal power plant with concentrating solar power and thermal storage to increase power generation and dispatchability." Applied Energy $228 \quad$ (2018): 1837-1852. https://doi.org/10.1016/i.apenergy.2018.07.064

[17] Bassetti, Martina Ciani, Daniele Consoli, Giovanni Manente, and Andrea Lazzaretto. "Design and off-design models of a hybrid geothermal-solar power plant enhanced by a thermal storage." Renewable Energy 128 (2018): $460-472$. https://doi.org/10.1016/i.renene.2017.05.078

[18] Wan, Peipei, Liang Gong, and Zhang Bai. "Thermodynamic analysis of a geothermal-solar flash-binary hybrid power generation system." Energy Procedia 158 (2019): 3-8. https://doi.org/10.1016/i.egypro.2019.01.023

[19] Sayad, Bouthaina, Djamel Alkama, Redha Rebhi, Younes Menni, Hijaz Ahmad, Mustafa Inc, Mohsen Sharifpur, Giulio Lorenzini, Ehab Azab, and Ashraf Y. Elnaggar. "Outdoor Thermal Comfort Optimization through Vegetation Parameterization: Species and Tree Layout." Sustainability 13, no. $21 \quad$ (2021): 11791. https://doi.org/10.3390/su132111791

[20] Shaari, Abdul Muin, Kamil Abdullah, Mohd Faizal Mohideen Batcha, Hamidon Salleh, and Makatar Wae-Hayee. "Effect of Converging Duct on Solar Chimney." CFD Letters 12, no. 3 (2020): 89-97. https://doi.org/10.37934/cfdl.12.3.8997

[21] Johnson, Zwalnan Selfa, Abakar Yousif Abdalla, Shanmugam Anandan, Chan Andy Tak-Yee, and Su Yuehong. "A Numerical Evaluation of the Effect of Building Thermal Load on the Overall Performance Characteristic of a GridCoupled PV/T Energy System." Journal of Advanced Research in Numerical Heat Transfer 4, no. 1 (2021): 32-43.

[22] Nasreddine, Sakhri, Draoui Belkacem, and Menni Younes. "Experimental study of earth to air heat exchanger performance in arid regions. First step: in-situ measurement of ground vertical temperature profile for different depths." Journal of Advanced Research in Fluid Mechanics and Thermal Sciences 56, no. 2 (2019): 183-194.

[23] Sakhri, Nasreddine, Abdeljabar Moussaoui, Younes Menni, Milad Sadeghzadeh, and Mohammad Hosein Ahmadi. "New passive thermal comfort system using three renewable energies: Wind catcher, solar chimney and earth to air heat exchanger integrated to real-scale test room in arid region (Experimental study)." International Journal of Energy Research 45, no. 2 (2021): 2177-2194. https://doi.org/10.1002/er.5911

[24] Sayad, Bouthaina, Djamel Alkama, Redha Rebhi, Ali Kidar, Giulio Lorenzini, Hijaz Ahmad, and Younes Menni. "Enhanced Outdoor Thermal Comfort Through Natural Design Technique: In-Situ Measurement and Microclimate Simulation." Instrumentation, Mesures, Métrologies 20, no. 3 (2021). https://doi.org/10.18280/i2m.200302

[25] Sayad, Bouthaina, Djamel Alkama, Hijaz Ahmad, Jamel Baili, Noufe H. Aljahdaly, and Younes Menni. "Nature-based solutions to improve the summer thermal comfort outdoors." Case Studies in Thermal Engineering 28 (2021): 101399. https://doi.org/10.1016/j.csite.2021.101399

[26] Nahoui, Azzedine, Redha Rebhi, Giulio Lorenzini, and Younes Menni. "Numerical Study of a Basin Type Solar Still with a Double Glass Cover Under Winter Conditions." Journal of Advanced Research in Fluid Mechanics and Thermal Sciences 88, no. 1 (2021): 35-48. https://doi.org/10.37934/arfmts.88.1.3548

[27] Boursas, Abdelhakim, Mohamed Salmi, Giulio Lorenzini, Hijaz Ahmad, Younes Menni, Djamal Fridja, Rachid Chebbi et al. "Enhanced Heat Transfer by Oil/Multi-Walled Carbon Nano-Tubes Nanofluid." In Annales de Chimie-Science des Matériaux, vol. 45, no. 2, pp. 93-103. 2021. https://doi.org/10.18280/acsm.450201

[28] Naima, Khatir, Younes Menni, Mounir Alliche, Giulio Lorenzini, Hijaz Ahmad, and Abdelkrim Liazid. "Effect of EGR on Performances and Emissions of DI Diesel Engine Fueled with Waste Plastic Oil: CDF Approach." In Annales de Chimie-Science des Matériaux, vol. 45, no. 3, pp. 217-223. 2021. https://doi.org/10.18280/acsm.450304

[29] Menni, Younes, A. Chamkha, Chafika Zidani, and Boumédiène Benyoucef. "Heat and nanofluid transfer through baffled channels in different outlet models." Mathematical Modelling of Engineering Problems 6, no. 1 (2019): 2128. https://doi.org/10.18280/mmep.060103

[30] Chamkha, Ali J., and Younes Menni. "Hydrogen flow over a detached v-shaped rib in a rectangular channel." Mathematical Modelling of Engineering Problems 7 (2020): 178-186. https://doi.org/10.18280/mmep.070202

[31] Menni, Younes, Ali J. Chamkha, Chafika Zidani, and Boumédiène Benyoucef. "Numerical analysis of heat and nanofluid mass transfer in a channel with detached and attached baffle plates." Mathematical Modelling of Engineering Problems 6, no. 1 (2019): 52-60. https://doi.org/10.18280/mmep.060107 
[32] Menni, Younes, A. Chamkha, Giulio Lorenzini, and Boumédiène Benyoucef. "Computational fluid dynamics based numerical simulation of thermal and thermo-hydraulic performance of a solar air heater channel having various ribs on absorber plates." Mathematical Modelling of Engineering Problems 6, no. 2 (2019): 170-174. https://doi.org/10.18280/mmep.060203

[33] Abderrahim, Asma, Nassera Ghellai, Zakaria Bouzid, and Younes Menni. "Wind energy resource assessment in south western of Algeria." Mathematical Modelling of Engineering Problems 6, no. 2 (2019): $157-162$. https://doi.org/10.18280/mmep.060201

[34] Mandi, Benaissa, Younes Menni, Rachid Maouedj, Giulio Lorenzini, Mohammad Hossein Ahmadi, and Sampath Emani. "Improvement and Nocturnal Extension of the Efficiency of a Solar Still." International Journal of Photoenergy 2021 (2021). https://doi.org/10.1155/2021/6631121

[35] Menni, Younes, Ali J. Chamkha, Ahmed Azzi, and Chafika Zidani. "Numerical analysis of fluid flow and heat transfer characteristics of a new kind of vortex generators by comparison with those of traditional vortex generators." International Journal of Fluid Mechanics Research 47, no. 1 (2020): 23-42. https://doi.org/10.1615/InterJFluidMechRes.2019026753

[36] Menni, Younes, Ali J. Chamkha, Chafika Zidani, and Boumédiène Benyoucef. "Heat Transfer in Air Flow Past a Bottom Channel Wall-Attached Diamond-Shaped Baffle-Using a CFD Technique." Periodica Polytechnica Mechanical Engineering 63, no. 2 (2019): 100-112. https://doi.org/10.3311/PPme.12490

[37] Menni, Younes, Giulio Lorenzini, Ravinder Kumar, Babak Mosavati, and Saeed Nekoonam. "Aerodynamic Fields inside S-Shaped Baffled-Channel Air-Heat Exchangers." Mathematical Problems in Engineering 2021 (2021). https://doi.org/10.1155/2021/6648403

[38] Menni, Younes, Ahmed Azzi, Ali J. Chamkha, and Souad Harmand. "Effect of wall-mounted V-baffle position in a turbulent flow through a channel: Analysis of best configuration for optimal heat transfer." International Journal of Numerical Methods for Heat \& Fluid Flow 29, no. 10 (2019): 3908-3937. https://doi.org/10.1108/HFF-06-2018-0270

[39] Menni, Younes, Ali J. Chamkha, and Ahmed Azzi. "Fluid flow and heat transfer over staggered '+ ' shaped obstacles." Journal of Applied and Computational Mechanics 6, no. 4 (2020): 741-756.

[40] Menni, Younes, Ahmed Azzi, and Ali Chamkha. "The solar air channels: comparative analysis, introduction of arcshaped fins to improve the thermal transfer." Journal of Applied and Computational Mechanics 5, no. 4 (2019): 616626.

[41] Menni, Younes, Ahmed Azzi, and Ali Jawad Chamkha. "Turbulent heat transfer and fluid flow over complex geometry fins." In Defect and Diffusion Forum, vol. 388, pp. 378-393. Trans Tech Publications Ltd, 2018. https://doi.org/10.4028/www.scientific.net/DDF.388.378

[42] Al-Sulaiman, Fahad A. "Exergy analysis of parabolic trough solar collectors integrated with combined steam and organic Rankine cycles." Energy Conversion and Management $77 \quad$ (2014): $441-449$. https://doi.org/10.1016/i.enconman.2013.10.013

[43] Tchanche, Bertrand Fankam, George Papadakis, Gregory Lambrinos, and Antonios Frangoudakis. "Fluid selection for a low-temperature solar organic Rankine cycle." Applied Thermal Engineering 29, no. 11-12 (2009): 2468-2476. https://doi.org/10.1016/i.applthermaleng.2008.12.025

[44] DiPippo, Ronald. Geothermal Power Plants: Principles, Applications, Case Studies and Environmental Impact. Butterworth-Heinemann, 2012.

[45] Baghernejad, A., and M. Yaghoubi. "Energy, exergy and second law performance of parabolic trough collector integration into combined cycle system (ISCCS)." In Proceedings of the Fourth International Conference on Thermal Engineering: Theory and Applications. Abu Dhabi (UAE), pp. 12-14. 2009.

[46] Boghossian, John G. "Dual-temperature Kalina cycle for geothermal-solar hybrid power systems." PhD diss., Massachusetts Institute of Technology, 2011.

[47] Saibi, Hakim. "Geothermal resources in Algeria." Renewable and Sustainable Energy Reviews 13, no. 9 (2009): $2544-$ 2552. https://doi.org/10.1016/i.rser.2009.06.019

[48] Mefti, A., M. Y. Bouroubi, and H. Mimouni. "Evaluation du potentiel énergétique solaire." Bulletin des Énergies Renouvelables 2 (2002).

[49] Wang, Jianyong, Jiangfeng Wang, Yiping Dai, and Pan Zhao. "Thermodynamic analysis and optimization of a flashbinary geothermal power generation system." Geothermics $55 \quad$ (2015): 69-77. https://doi.org/10.1016/j.geothermics.2015.01.012

[50] Guzović, Zvonimir, Boris Majcen, and Svetislav Cvetković. "Possibilities of electricity generation in the Republic of Croatia from medium-temperature geothermal sources." Applied Energy 98 (2012): 404-414. https://doi.org/10.1016/j.apenergy.2012.03.064 